\title{
Correction to: Safety and feasibility of retrograde INOUE-BALLOON for balloon aortic valvuloplasty without rapid ventricular pacing during transcatheter aortic valve replacement
}

\author{
Ryo Ninomiya $^{1}$ (D) - Michiko Yoshizawa ${ }^{1} \cdot$ Yorihiko Koeda $^{1} \cdot$ Yu Ishikawa ${ }^{1} \cdot$ Akiko Kumagai $^{1} \cdot$ Masaru Ishida $^{1}$. \\ Fumiaki Takahashi ${ }^{2} \cdot$ Tetsuya Fusazaki $^{1}$ - Atsushi Tashiro ${ }^{3} \cdot$ Hajime Kin $^{4} \cdot$ Yoshihiro Morino $^{1}$
}

Published online: 12 November 2021

(c) The Author(s) 2021

\section{Correction to: \\ Cardiovascular Intervention and Therapeutics https://doi.org/10.1007/s12928-021-00789-0}

In the original publication of the article, in table 1, there was an error in the number of conventional balloons used. This was because we had originally enrolled 132 patients and the entry was left out. The study ended up including 104 patients who used the Conventional Balloon. The $100 \%$ rate remains the same because rapid pacing is still being done in all patients.
Table 1 Baseline patient and procedural characteristics

\begin{tabular}{|c|c|c|c|c|}
\hline & Page & Line & Error & Correction \\
\hline$\# 1$ & 5 & 33 (Table 1) & $132(100)$ & $104(100)$ \\
\hline$\# 2$ & 7 & 21 (Table 4) & $\begin{array}{l}\text { Long RVP } \\
\quad(>35 \mathrm{~ms})\end{array}$ & Long RVP (> 35 s) \\
\hline \#3 & 8 & 50 & $\begin{array}{l}\text { The authors are } \\
\text { deeply grateful } \\
\text { to the labora- } \\
\text { tory members } \\
\text { Yumiko Okuyama } \\
\text { (research nurse), } \\
\text { Kayoko Fujiwara, } \\
\text { and Kanako } \\
\text { Omiya (secretar- } \\
\text { ies) }\end{array}$ & $\begin{array}{l}\text { The authors are } \\
\text { deeply grateful } \\
\text { to the labora- } \\
\text { tory members } \\
\text { Yumiko Okuyama } \\
\text { (research nurse), } \\
\text { Kayoko Fujiwara, } \\
\text { and Kanako } \\
\text { Omiya (secretar- } \\
\text { ies). This work } \\
\text { was supported by } \\
\text { JSPS KAKENHI } \\
\text { Grant Number JP } \\
\text { 20K17093 }\end{array}$ \\
\hline
\end{tabular}

The original article can be found online at https://doi.org/10.1007/ s12928-021-00789-0.

Ryo Ninomiya

rnino@iwate-med.ac.jp

1 Division of Cardiology, Department of Internal Medicine, Iwate Medical University, 2-1-1, Idaidori, Yahaba, Iwate 028-3694, Japan

2 Division of Medical Engineering, Department of Information Science, Center for Liberal Arts and Sciences, Iwate Medical University, Iwate, Japan

3 Department of Laboratory of Medicine, Iwate Medical University, Iwate, Japan

4 Department of Cardiovascular Surgery, Iwate Medical University, Iwate, Japan 
Table 4 Univariate and multivariate logistic regression analysis of predictors for prolonged hypotension post BAV

\begin{tabular}{|c|c|c|c|c|c|c|}
\hline & \multicolumn{3}{|c|}{ Univariate analysis } & \multicolumn{3}{|c|}{ Multivariate analysis } \\
\hline & OR & $95 \% \mathrm{CI}$ & $p$ value & OR & $95 \% \mathrm{CI}$ & $p$ value \\
\hline Male & 1.40 & $0.578-3.731$ & 0.419 & & & \\
\hline Age & 1.02 & $0.930-1.123$ & 0.645 & & & \\
\hline NYHA $>3$ & 0.91 & $0.250-3.367$ & 0.896 & & & \\
\hline Hypertension & 0.46 & $0.162-1.306$ & 0.145 & & & \\
\hline Diabetes & 2.26 & $0.858-5.952$ & 0.099 & & & \\
\hline Atrial fibrillation & 2.97 & $1.111-7.920$ & 0.023 & 2.53 & $0.886-6.929$ & 0.081 \\
\hline Coronary revascularization & 1.96 & $0.727-5.307$ & 0.183 & & & \\
\hline eGFR & 0.99 & $0.964-1.019$ & 0.517 & & & \\
\hline BNP & 1.00 & $0.999-1.000$ & 0.969 & & & \\
\hline LVEF (Simpson) & 0.98 & $0.941-1.029$ & 0.488 & & & \\
\hline AVA-I & 0.77 & $0.032-18.946$ & 0.137 & & & \\
\hline LVEDV & 0.99 & $0.970-1.012$ & 0.356 & & & \\
\hline LVESV & 1.01 & $0.978-1.035$ & 0.671 & & & \\
\hline Balloon size & 0.98 & $0.941-1.029$ & 0.488 & & & \\
\hline RVP time & 1.03 & $0.992-1.060$ & 0.140 & & & \\
\hline Long RVP (> 35 s) & 2.84 & $1.034-7.510$ & 0.043 & 1.59 & $0.534-4.594$ & 0.396 \\
\hline INOUE-BALLOON without RVP & 0.22 & $0.061-0.768$ & 0.018 & 0.27 & $0.059-0.952$ & 0.041 \\
\hline
\end{tabular}

AVA-I AVA indexed, $e G F R$ estimated glomerular filtration rate, $L V E D V$ left ventricular end-diastolic volume, $L V E F$ left ventricular ejection fraction, $L V E S V$ left ventricular end-systolic volume, $M I$ myocardial infarction, NYHA New York Heart Association, RVP rapid ventricular pacing
In Table 4, Long RVP is $35 \mathrm{~s}$ is the correct information.

In the original publication of the article, the acknowledgements section published incorrectly. The correct acknowledgements is given in this correction.

\section{Acknowledgements}

This work was supported by JSPS KAKENHI Grant Number JP 20K17093. The authors are deeply grateful to the laboratory members Yumiko Okuyama (research nurse), Kayoko Fujiwara, and Kanako Omiya (secretaries).

The original article has been corrected.
Open Access This article is licensed under a Creative Commons Attribution 4.0 International License, which permits use, sharing, adaptation, distribution and reproduction in any medium or format, as long as you give appropriate credit to the original author(s) and the source, provide a link to the Creative Commons licence, and indicate if changes were made. The images or other third party material in this article are included in the article's Creative Commons licence, unless indicated otherwise in a credit line to the material. If material is not included in the article's Creative Commons licence and your intended use is not permitted by statutory regulation or exceeds the permitted use, you will need to obtain permission directly from the copyright holder. To view a copy of this licence, visit http://creativecommons.org/licenses/by/4.0/.

Publisher's Note Springer Nature remains neutral with regard to jurisdictional claims in published maps and institutional affiliations. 